\title{
Guidelines for overcoming hospital managerial challenges: a systematic literature review
}

This article was published in the following Dove Press journal:

Therapeutics and Clinical Risk Management

30 October 2013

Number of times this article has been viewed

\author{
Maria Crema \\ Chiara Verbano \\ Department of Management and \\ Engineering, University of Padova, \\ Vicenza, Italy
}

Correspondence: Chiara Verbano Department of Management and Engineering, University of Padova, Stradella San Nicola 3,

36100 Vicenza, Italy

Tel +390444998 73I

Fax +390444998888

Email chiara.verbano@unipd.it
Purpose: The need to respond to accreditation institutes' and patients' requirements and to align health care results with increased medical knowledge is focusing greater attention on quality in health care. Different tools and techniques have been adopted to measure and manage quality, but clinical errors are still too numerous, suggesting that traditional quality improvement systems are unable to deal appropriately with hospital challenges. The purpose of this paper is to grasp the current tools, practices, and guidelines adopted in health care to improve quality and patient safety and create a base for future research on this young subject.

Methods: A systematic literature review was carried out. A search of academic databases, including papers that focus not only on lean management, but also on clinical errors and risk reduction, yielded 47 papers. The general characteristics of the selected papers were analyzed, and a content analysis was conducted.

Results: A variety of managerial techniques, tools, and practices are being adopted in health care, and traditional methodologies have to be integrated with the latest ones in order to reduce errors and ensure high quality and patient safety. As it has been demonstrated, these tools are useful not only for achieving efficiency objectives, but also for providing higher quality and patient safety. Critical indications and guidelines for successful implementation of new health managerial methodologies are provided and synthesized in an operative scheme useful for extending and deepening knowledge of these issues with further studies.

Conclusion: This research contributes to introducing a new theme in health care literature regarding the development of successful projects with both clinical risk management and health lean management objectives, and should address solutions for improving health care even in the current context of decreasing resources.

Keywords: health lean management, patient safety, clinical errors, health care quality, clinical process improvement

\section{Introduction Quality in health care}

Society is no longer prepared to accept the number of clinical errors that are reported by the mass media. Nowadays, accreditation requirements, the needs and expectations of patients, and social and ethical values demand continuous improvement in the quality of health care, while maintaining costs the same time.

The literature provides different definitions of quality in health care. These are usually generic or disaggregated, and different features of quality are usually highlighted from the diverse perspectives of stakeholders. ${ }^{1,2}$ 
Martin has defined quality as meeting or exceeding predefined standards; ${ }^{3}$ other authors have described quality as the extent to which the desired health outcomes or the expectations of patients and other customers of health care services are met. ${ }^{4,5}$ According to the Agency for Healthcare Research and Quality, ${ }^{6}$ it is doing the right thing at the right time in the right way for the right person and having the best possible results. Based on the work of Spear and Bowen ${ }^{7}$ in an industrial context, Condel et $\mathrm{al}^{8}$ and Printezis and Gopalakrishnan ${ }^{9}$ have added that health care services should be: guaranteed every time, defect-free, and provided in a safe environment at the lowest cost and without waste. In particular, the Agency for Healthcare Research and Quality ${ }^{10}$ and a report by the Institute of Medicine ${ }^{11}$ have underscored that to ensure high quality, health care services should be: safe, timely, patientcentered, efficient, effective, and equitable. One of the most cited definitions considers health care quality as the "degree to which health services for individuals and populations increase the likelihood of desired health outcomes and are consistent with current professional knowledge". ${ }^{12}$

Donabedian ${ }^{13}$ has recognized that different quality measurement and management systems have to be associated with different definitions of quality, according to different perspectives. In the last two decades, several quality improvement approaches have been implemented in hospitals. However, these have yielded unsatisfactory results, with errors remaining a feature of health care. Such errors are mainly due to the way employees work. Traditional quality improvement initiatives that assume a retrospective and not system-wide approach do not allow proper reduction and prevention of errors. They include quality control, quality assurance, continuous improvement, and six sigma (SS). ${ }^{14-17}$

Vincent ${ }^{18}$ defined clinical risks as the "dark side" of quality, so to improve quality it is necessary to reduce and/or avoid errors in health care. According to McCulloch et al, ${ }^{19}$ an error can be defined as any unintended or unexpected incident that could harm one or more patients.

Errors can be divided into the following: sentinel events (that give rise to legal action), adverse events (unfavorable patient outcome, but not severe), no-harm events (affects patients but does not harm them), and near-misses (errors prevented thanks to timely corrective actions, usually through direct observations). ${ }^{20,21}$ To ensure patient safety, health care structures or processes are needed to reduce the probability of adverse events resulting from exposure to the health care system. ${ }^{17}$ It is necessary to focus on processes and systems and to implement new practices and barriers using an organization-wide approach. ${ }^{9,22,23}$ "Errare humanum est" ("to err is human") and the human condition cannot be changed. However, the conditions under which people work can be changed to help them avoid mistakes, even in complex settings. Verbano and Turra ${ }^{24}$ and Verbano and Venturini ${ }^{25}$ have stated that different tools can be adopted in a clinical risk management (CRM) approach. Others report that systematic methods from the industrial sector could be effective in reducing medical errors, such as total quality management (TQM), quality function deployment, plan do check act (PDCA), zero defects, and lean thinking. ${ }^{26,27}$ Lean thinking is a philosophy and an organizational way of work; following its recent meaning, it also incorporates SS. ${ }^{8,27}$

Lean management (LM) principles according to Womack and Jone ${ }^{28}$ are: precisely specify value, identify the value stream, make value flow without interruptions, pull approach, and continuous improvement pursuing perfection. Liker $^{29}$ has classified them in a different way, suggesting a 4P model, which includes: problem-solving (continuous improvement), people (respect, challenge, and grow), process (waste elimination), and philosophy (long-term thinking). Some new practices connected to LM that should overcome unsatisfactory results with previous tools are: lean total quality management (LTQM) ${ }^{30}$ the Henry Ford production system (HFPS), ${ }^{31}$ lean six sigma (LSS), ${ }^{27,31-33}$ and the Toyota production system (TPS). ${ }^{9}$

In health care, the definition given for health lean management (HLM) is:

"A management philosophy to develop a hospital culture characterized by increased patient and other stakeholder satisfaction through continuous improvements, in which all employees (managers, physicians, nurses, laboratory people, technicians, office people etc) actively participate in identifying and reducing non-value-adding activities (waste)." ${ }^{34}$

HLM practices were originally adopted mainly to improve efficiency, but they have the potential to improve quality and reduce errors, decrease time and costs, increase staff productivity, and improve patient outcomes and employee and customer satisfaction. ${ }^{27}$

HLM, in fact, could be described as a managerial approach for identifying and eliminating waste while improving the flow of activities to maximize customer value. ${ }^{35,28}$ It includes standardization and specification of work processes and organization in such a way that unexpected events can be spotted and activities that find and fix mistakes can be developed. Within these mistakes, clinical errors could be included, but, most of all, HLM can be 
used for clinical process analysis, which is necessary for detecting clinical risks, and tools and practices of HLM could also contribute to reducing errors (eg, use of mistake proofing [poka-yoke], 5S, and so on, could create a context that prevents risks of harm). HLM could be a way of reducing costs while maintaining high levels of patient safety and quality, eliminating any of the typical waste that we find in hospitals, such as overproduction, overprocessing, transportation, inventory, movement, waiting times, and defective products. ${ }^{36-38}$

The need for improved performance is the result of the hospital funding crisis, spending reviews, and increasing health care costs, mainly due to an aging population, the use of more advanced technologies, the lack of cost-containment measures, inefficiencies, and medical errors. ${ }^{9,39-43}$ Kumar and Steinebach ${ }^{44}$ have recognized the direct costs (higher health care expenditures) and indirect costs (lower productivity, disability, and personal care) of poor quality. Others have noted that poor quality has financial implications and leads to low patient trust and low staff and patient satisfaction. ${ }^{9}$ Some authors have emphasized that quality improvement can offer financial benefits for the whole health system. ${ }^{43,45}$ The adoption of HLM and other managerial tools and practices could be useful for achieving these results.

Based on the aforementioned issues, the purpose of this paper is to investigate the new practices and the key critical factors adopted and suggested in the literature not only to reduce costs, but also to ensure a high level of quality and safety. In particular, two main purposes will be pursued:

1. To give an overview of the managerial techniques, tools, and practices adopted for the implementation of projects connecting, even partially, HLM and CRM.

2. To grasp from the literature review the key critical factors that have to be considered for successful implementation of HLM projects that have an impact on CRM.

The intention of this work is to draw up potential/ hypothetical guidelines from the literature review to be tested and, if necessary, integrated into future studies, conducting empirical research in the field.

\section{Methods}

In order to achieve the aims described in the previous section, a systematic review of the literature was conducted, drawing on current methodologies. ${ }^{46-49}$ and answering the question: what are the tools, practices, and key critical factors needed to successfully implement HLM, stressing safety performance? In addition, our intention is to provide directions for fruitful future research.
The protocol for the systematic literature review included the following steps: a) conceptual discussion of the problem, b) definition of the literature review objective, c) search strategy, d) paper selection criteria, e) single-paper analysis, f) description of the main characteristics of the extracted papers, and f) synthesis of interesting content and lessons learned.

The academic databases searched were: Business Source Premier (EBSCO), Compendex (Ei Village 2), Inspec (Ei Village 2), Web of Science (ISI), and PubMed. The keywords employed are reported in the second column of Table 1, which also presents the selection criteria for the papers and the results of the search strategy. In particular, research was carried out by two researchers that followed the same steps. After cutting out any duplications and reading the title and the abstract of the papers, each researcher, working independently, eliminated papers that did not consider managerial aspects or LM. Papers that did not go in depth (eg, opinion papers, lecture notes, papers of 2-3 pages) were not included in the analysis. Following the context, interventions, mechanisms and outcomes (CIMO) logic suggested by Denyer et $\mathrm{al}^{48}$ for organization and management research, after the full reading of articles, other papers were deleted from the database. The context of the research is a hospital, so papers not focusing on this context were excluded and, according to the purpose of the research, only papers that analyzed lean health care and its relationship with patient safety (for example in defining objectives or analyzing results obtained) were included in order to study the adopted interventions and mechanisms and the achieved outcomes (IMO).

In the single-paper analysis, the following was recorded: citations, authors, title of the paper, year, keywords, principal theme, name of the journal, impact factor and $\mathrm{H}$-index of the journal, research methodology, aim of the paper, results, authors' backgrounds, context of applicability, notes about key concepts, number of authors, and country where the study was conducted. Papers were examined based on their descriptive characteristics, and content analysis was then conducted to identify the main issues and lessons learned in the existing literature.

Table 2 shows the main characteristics of the papers included in the review. Most of the papers had more than one author, and all the journals but one had an $\mathrm{H}$-index greater than 8 , even if not all of them were present in the ISI list. With respect to the workplace of the first author, most of the papers were from the US (78\%), followed by the UK (9\%) and Sweden (4\%). With regard to the year of publication, a positive trend emerged: $13 \%$ of the papers were published from 2004 to 2005, 17\% from 2006 to 2007, 24\% from 2008 
Table I Search strategy and paper selection

\begin{tabular}{|c|c|c|c|}
\hline \multirow[t]{2}{*}{ Database } & \multirow[t]{2}{*}{ Keywords } & \multicolumn{2}{|l|}{ Total papers: I348 } \\
\hline & & Selection criteria & $\begin{array}{l}\text { Number of papers } \\
\text { after selection }\end{array}$ \\
\hline $\begin{array}{l}\text { - Web of Science (ISI) } \\
\text { - PubMed } \\
\text { - Business Source Premier (EBSCO) } \\
\text { - Compendex (Ei Village 2) } \\
\text { - Inspec (Ei Village 2) }\end{array}$ & $\begin{array}{l}\text { CRM "and" lean health care } \\
\text { Lean management "and" CRM } \\
\text { Lean organization "and" CRM } \\
\text { Lean management "and" health RM } \\
\text { Lean organization "and" health RM } \\
\text { RM "and" lean health care } \\
\text { Lean hospital "and" CRM } \\
\text { Six sigma "and" CRM } \\
\text { Six sigma "and" medical error } \\
\text { Six sigma "and" clinical error } \\
\text { Lean "and" clinical error } \\
\text { Lean patient safety "without" obesity weight } \\
\text { Lean patient safety "without" obesity body }\end{array}$ & $\begin{array}{l}\text { Exclusion of duplications and papers } \\
\text { not useful to answer literature } \\
\text { review questions after reading } \\
\text { the title and the abstract. } \\
\text { No conference proceedings, } \\
\text { opinion papers, lecture notes } \\
\text { and papers of only I-3 pages, } \\
\text { papers with no references, and } \\
\text { non-English language papers. } \\
\text { CIMO: inclusion of papers whose } \\
\text { context was that of health care } \\
\text { providers, such as hospitals and } \\
\text { papers which consider lean health care } \\
\text { and its relationship with clinical errors } \\
\text { (even if they are only mentioned in } \\
\text { the results or in the objectives; IMO). }\end{array}$ & 157 \\
\hline
\end{tabular}

Abbreviations: CIMO, context, interventions, mechanisms, and outcomes; CRM, clinical resource management; IMO, interventions, mechanisms and achieved outcomes; RM, resource management.

to 2009 , and $46 \%$ from 2010 to 2013 . As for the adopted methodology, most of the papers conducted case or action research (63\%); there was just one simulation and no surveys. Literature reviews were included as they study previous experiences and/or because they give new suggestions for future research that could be useful, considering the scope of this research. Regarding the context of applicability, $67 \%$ of papers focused only on a single unit or department of a hospital (mostly laboratory department, emergency department, radiology and gynecology departments), 24\% studied a hospital as a whole (HG), 7\% analyzed a single care process (PC), and $2 \%$ dealt with the collaboration and the alignment between the emergency department and other areas of a hospital.

\section{Content analysis of previous studies}

In Table 3, the main purposes of the papers, the tools and practices considered, and the benefits of their application are reported. Managerial tools and practices are categorized as follows:

- Information and communication technologies (ICT), including, for example, pathology informatics, electronic medical records (EMR), optical character recognition, 24-hour hotlines, web-based reporting systems, new tools for communication and teamwork, online medication ordering systems, and decision-support systems (DSS), such as event monitoring, alarms and alerts systems, "andon", patient safety alerts, and decision-making models.
- Process management. These tools and practices are classified according to the phases where they are usually adopted: understanding and mapping (eg, value stream analysis), planning (eg, hoshin planning, "to be" map, corrective action plan), standardization and specification (eg, instructions and guidelines, standardized reporting, and nomenclature), improvement (eg, rapid improvement events, kaizen, 5S), and monitoring and control (eg, visual control, weekly audit, management dashboards).

- Quality management, including indicators of quality, quality control, quality assurance, use of six sigma and define, measure analyze, improve, and control (DMAIC), quality management systems (QMS), continuous quality improvement programs, total quality management (TQM) practices, quality function deployment/house of quality (QFD/HOQ), and ISO 9000.

- Compliance consists of auditing to monitor the results of compliance, and adopting well-accepted guidelines, universal protocols.

- Error management. These tools and practices are classified according to four phases: identification (eg, error reporting and error detection system, error documentation, error inspection), analysis (eg, RCA, FMEA, risk assessment tool, 5 whys, Ishikawa diagram, etc), prevention and correction (eg, poka-yoke, stop the line), and monitoring and control (eg, error audit and feedback). 
Table 2 Characteristics of the selected papers

\begin{tabular}{|c|c|c|c|c|c|c|}
\hline $\mathbf{N}$ & Authors & $\begin{array}{l}\text { Research } \\
\text { methodology }\end{array}$ & Field & $\begin{array}{l}\text { Journal } \\
\text { classification }\end{array}$ & $\mathbf{N}$ of authors & $\begin{array}{l}\text { Paper } \\
\text { country* }\end{array}$ \\
\hline I & Becich et $\mathrm{al}^{50}$ & Literature review & Laboratory (LAB) & Med & 6 & USA \\
\hline 2 & Benitez et $\mathrm{al}^{51}$ & Field research** & Hospital in General (HG) & MAn & 4 & USA \\
\hline 3 & Berte $^{17}$ & Literature review & $\mathrm{LAB}$ & Man and Med & I & USA \\
\hline 4 & Biffl et $\mathrm{al}^{52}$ & Field research & Process of Care (PC) & Man & II & USA \\
\hline 5 & Buesa $^{31}$ & Literature review & $\mathrm{LAB}$ & Med & I & USA \\
\hline 6 & Condel et $\mathrm{al}^{8}$ & Case study & $\mathrm{LAB}$ & Med & 3 & USA \\
\hline 7 & $\mathrm{Das}^{30}$ & Case study & LAB & Med & I & India \\
\hline 8 & Esimai $^{53}$ & Case study & HG & Man & 1 & USA \\
\hline 9 & Furman $^{54}$ & Case study & HG & Man & 2 & USA \\
\hline 10 & Hintzen et $\mathrm{al}^{55}$ & Field research & Inpatient Pharmacy & Man and Med & 4 & USA \\
\hline II & Holden ${ }^{56}$ & Literature review & ED & Med & I & Sweden \\
\hline 12 & Hummel et $\mathrm{al}^{57}$ & Field research & ED & Med & 3 & USA \\
\hline 13 & Hurley et $\mathrm{al}^{58}$ & Field research & $\mathrm{LAB}$ & Man and Med & 4 & USA \\
\hline 14 & Johnson et $\mathrm{al}^{59}$ & Field research & Radiology & Med & 6 & USA \\
\hline 15 & Kim et $\mathrm{al}^{60}$ & Field research & PC & Med & 7 & USA \\
\hline 16 & Kruskal et $\mathrm{a}^{27}$ & Literature review & Radiographics & Med & 5 & USA \\
\hline 17 & Kumar and Steinebach ${ }^{44}$ & Literature review & HG & Man and Med & 2 & USA \\
\hline 18 & Kuo et $\mathrm{al}^{32}$ & Field research & Postanesthesia Care Unit & Man & 4 & Canada \\
\hline 19 & LaRocco and Brient ${ }^{61}$ & Field research & Pathology & Med & 2 & USA \\
\hline 20 & Martin $^{3}$ & Literature review & HG & Med & I & USA \\
\hline 21 & Mazzocato et $\mathrm{al}^{62}$ & Literature review & Many units, separately & Med & 5 & Sweden \\
\hline 22 & McCulloch et al ${ }^{19}$ & Field research & Surgical Emergency Unit & Med & 6 & UK \\
\hline 23 & Naik et al ${ }^{63}$ & Field research & collaboration and alignment & Med & 7 & USA \\
\hline 24 & Niemeijer et $\mathrm{al}^{64}$ & Field research & HG & Man and Med & 5 & Netherlands \\
\hline 25 & Novis ${ }^{22}$ & Literature review & $\mathrm{LAB}$ & Med & 1 & USA \\
\hline 26 & Pantanowitz et $\mathrm{al}^{65}$ & Literature review & $\mathrm{LAB}$ & Med & 3 & USA \\
\hline 27 & Pawlicki and Mundt ${ }^{23}$ & Literature review & Radiology & Med & 2 & USA \\
\hline 28 & Pocha ${ }^{39}$ & Field research & ED & Man and Med & 1 & USA \\
\hline 29 & Printezis and Gopalakrishnan ${ }^{9}$ & Literature review & HG & Man and Med & 2 & USA \\
\hline 30 & Raab et $a^{66}$ & Field research & Gynecology & Med & 4 & USA \\
\hline 31 & Raab et $a^{67}$ & Field research & Gynecology & Med & 9 & USA \\
\hline 32 & Radnor et $\mathrm{al}^{68}$ & Field research & many units, separately & Med & 3 & UK \\
\hline 33 & Schweikhart and Dembe ${ }^{69}$ & Field research & $\mathrm{LAB}$ & Med & 2 & USA \\
\hline 34 & Serrano et $\mathrm{al}^{70}$ & Field research & Pathology & Med & 5 & USA \\
\hline 35 & Sloane and Gehlot ${ }^{71}$ & Simulation & HG & Man & 2 & USA \\
\hline 36 & Smith et $\mathrm{al}^{21}$ & Action research & LAB & Med & 4 & USA \\
\hline 37 & Stankovic ${ }^{20}$ & Literature review & $\mathrm{LAB}$ & Med & 1 & USA \\
\hline 38 & Stankovic and DiLauri ${ }^{33}$ & Literature review & $\mathrm{LAB}$ & Med & 2 & USA \\
\hline 39 & Sunyog ${ }^{72}$ & Field research & LAB & Man and Med & 1 & USA \\
\hline 40 & Varkey and Kollengode ${ }^{26}$ & Literature review & HG & Med & 2 & USA \\
\hline 41 & Varkey et $\mathrm{al}^{73}$ & Literature review & HG & Med & 3 & USA \\
\hline 42 & Vats et $\mathrm{al}^{74}$ & Field research & Pediatric Intensive Care Unit & Med & 6 & USA \\
\hline 43 & Veluswamy and Price ${ }^{75}$ & Field research & HG & Med & 2 & USA \\
\hline 44 & Wilson $^{76}$ & Field research & Many units, separately & Man and Med & I & UK \\
\hline 45 & Yeh et $\mathrm{al}^{77}$ & Field research & PC & Man & 4 & Taiwan \\
\hline 46 & Zarbo et $\mathrm{al}^{78}$ & Field research & $\mathrm{LAB}$ & Med & 7 & USA \\
\hline
\end{tabular}

Notes: *Workplace of the first author; **field research: case study or action research.

Abbreviations: Man, management; Med, medical; N, number; ED, emergency department.

- People and culture, including use of an adequate team, black belt/consultant, employee training and education, lean facilitator and sensei (clinical champions), trystorming and brainstorming, learning organization, involvement and empowerment, employee satisfaction, top management commitment and support, development of the right culture and philosophy, and human quality management (model of behavior change).

- Customer/patient management. These tools and practices refer to the valorization of patients (add value, 


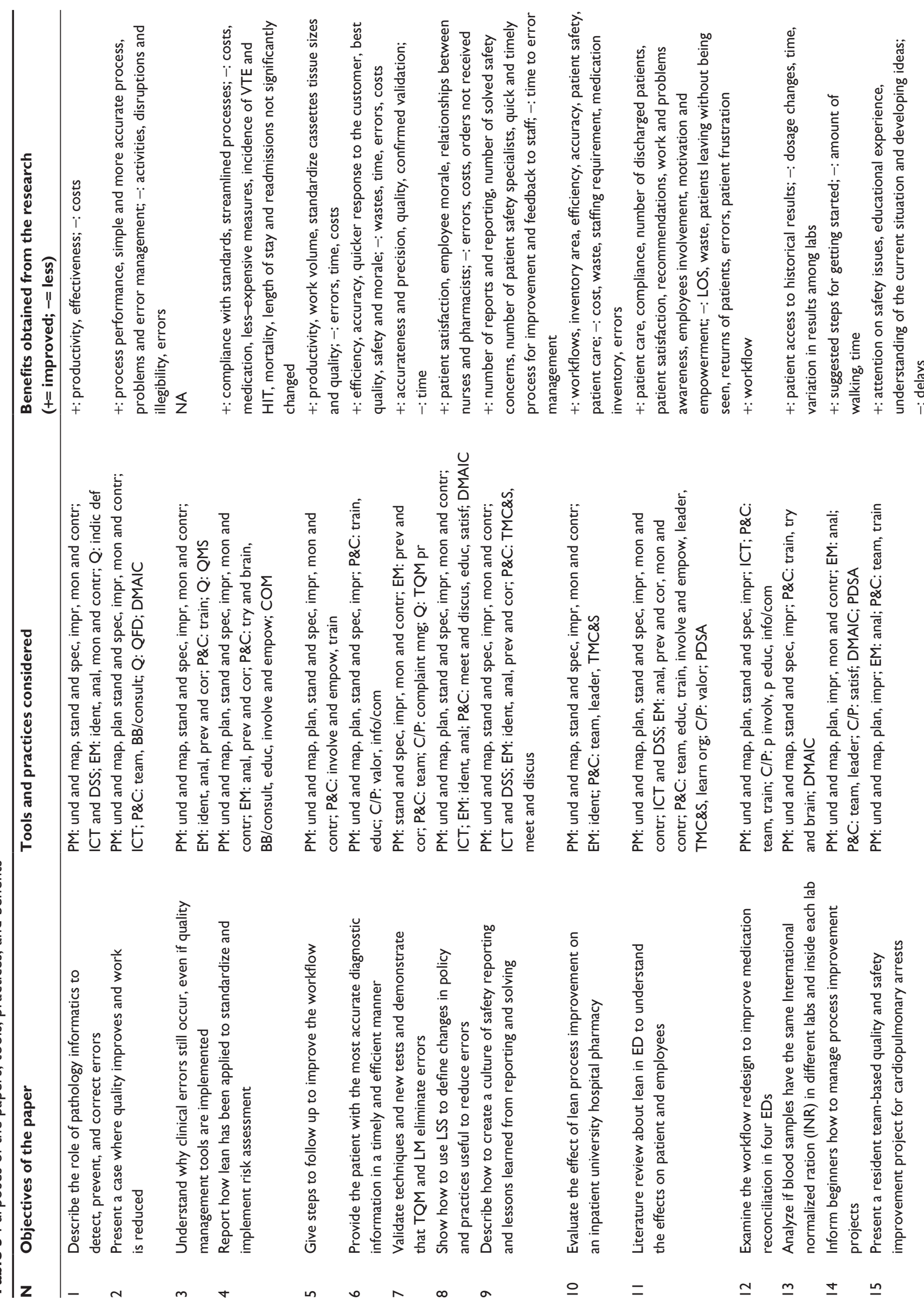



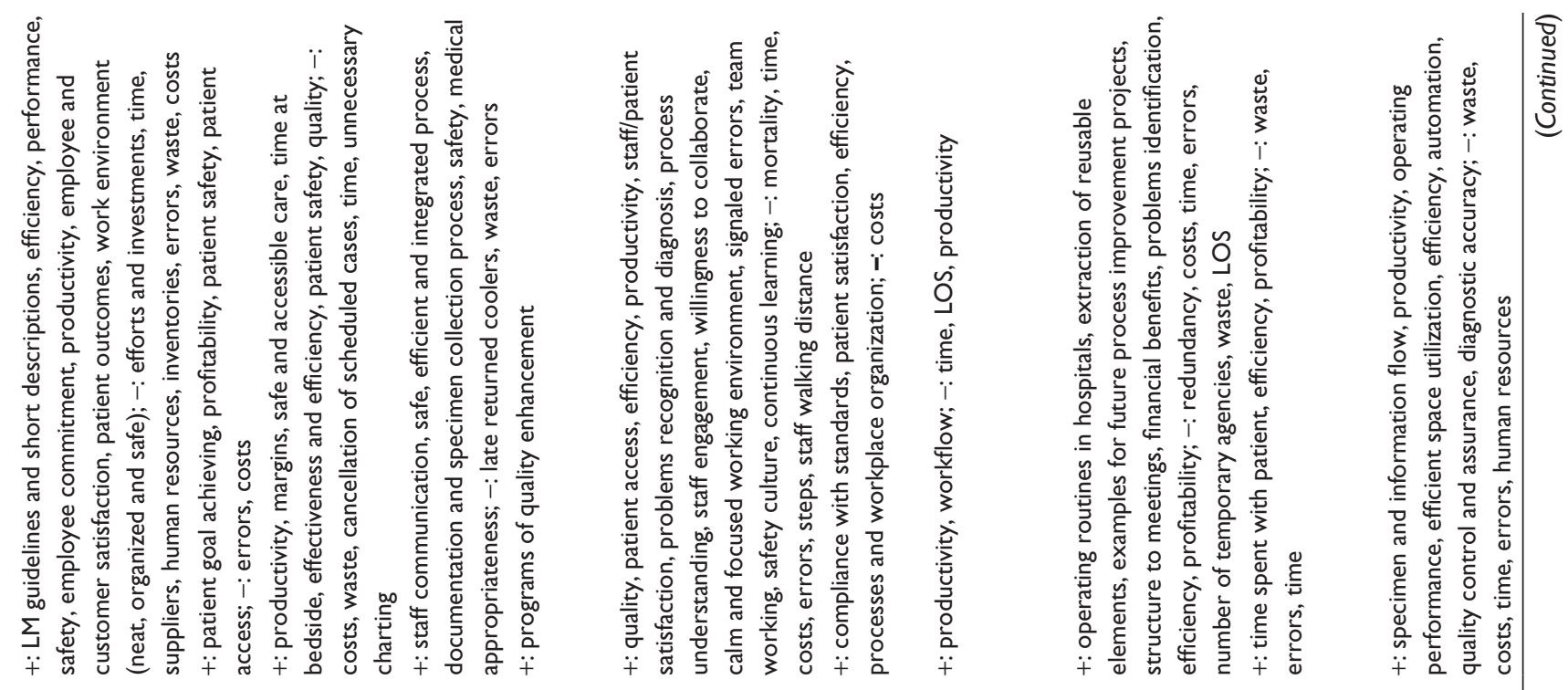

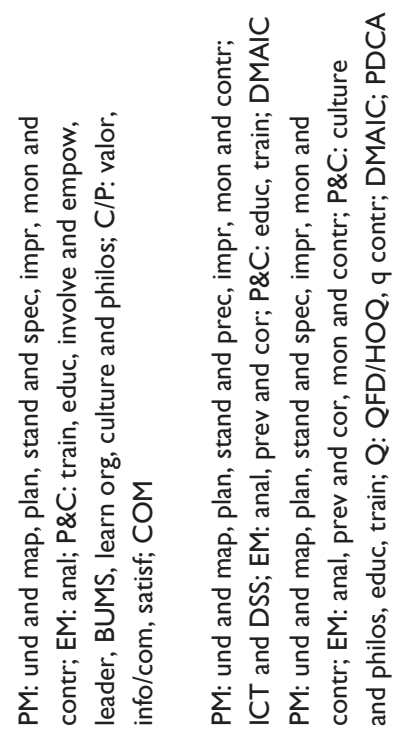
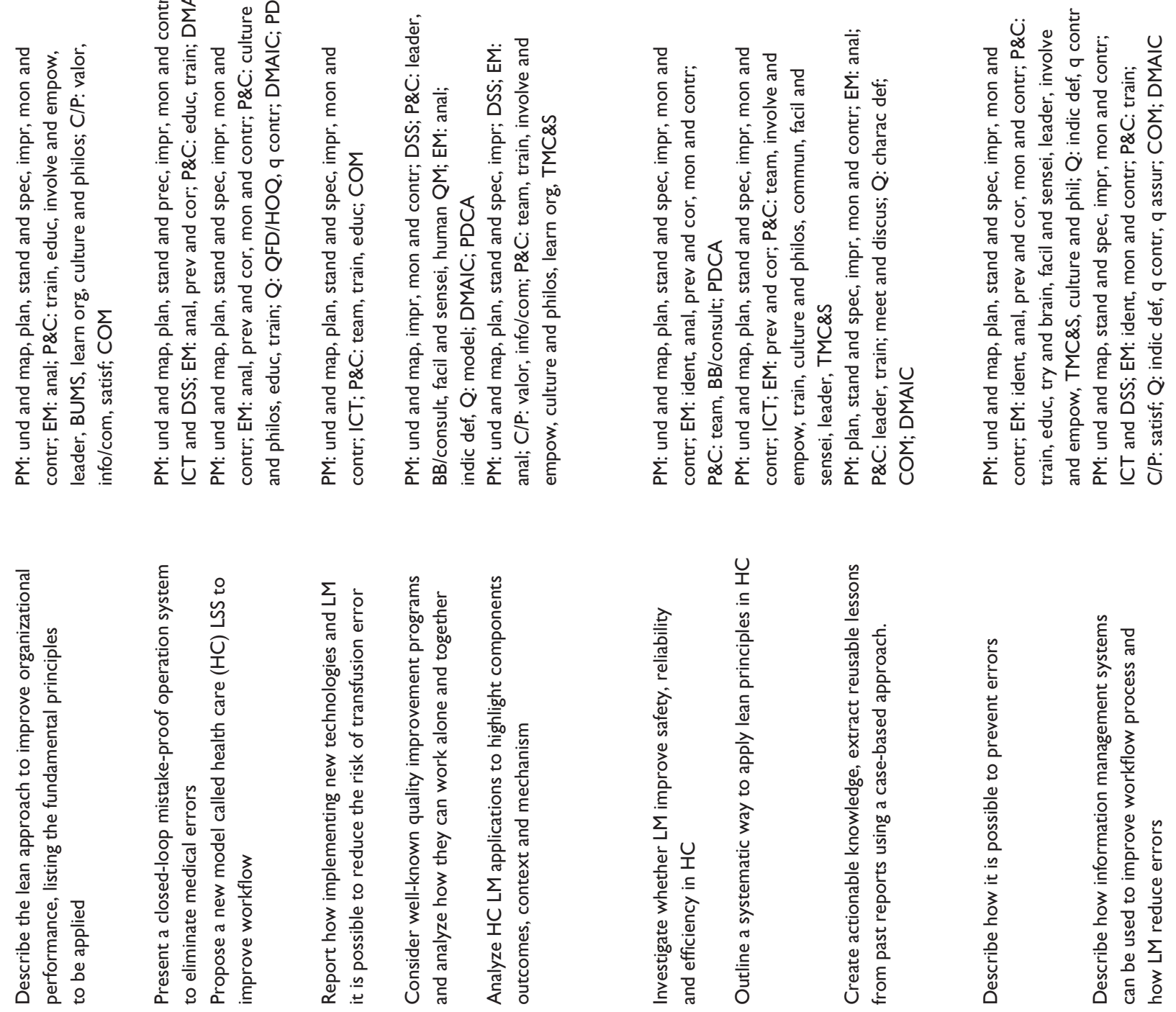

$\underline{\circ}$

$$
\leq \quad \leq \quad \stackrel{4}{\sim}
$$

ส ก

$\dot{4}$

$\stackrel{4}{2}$

$\stackrel{2}{2}$ 


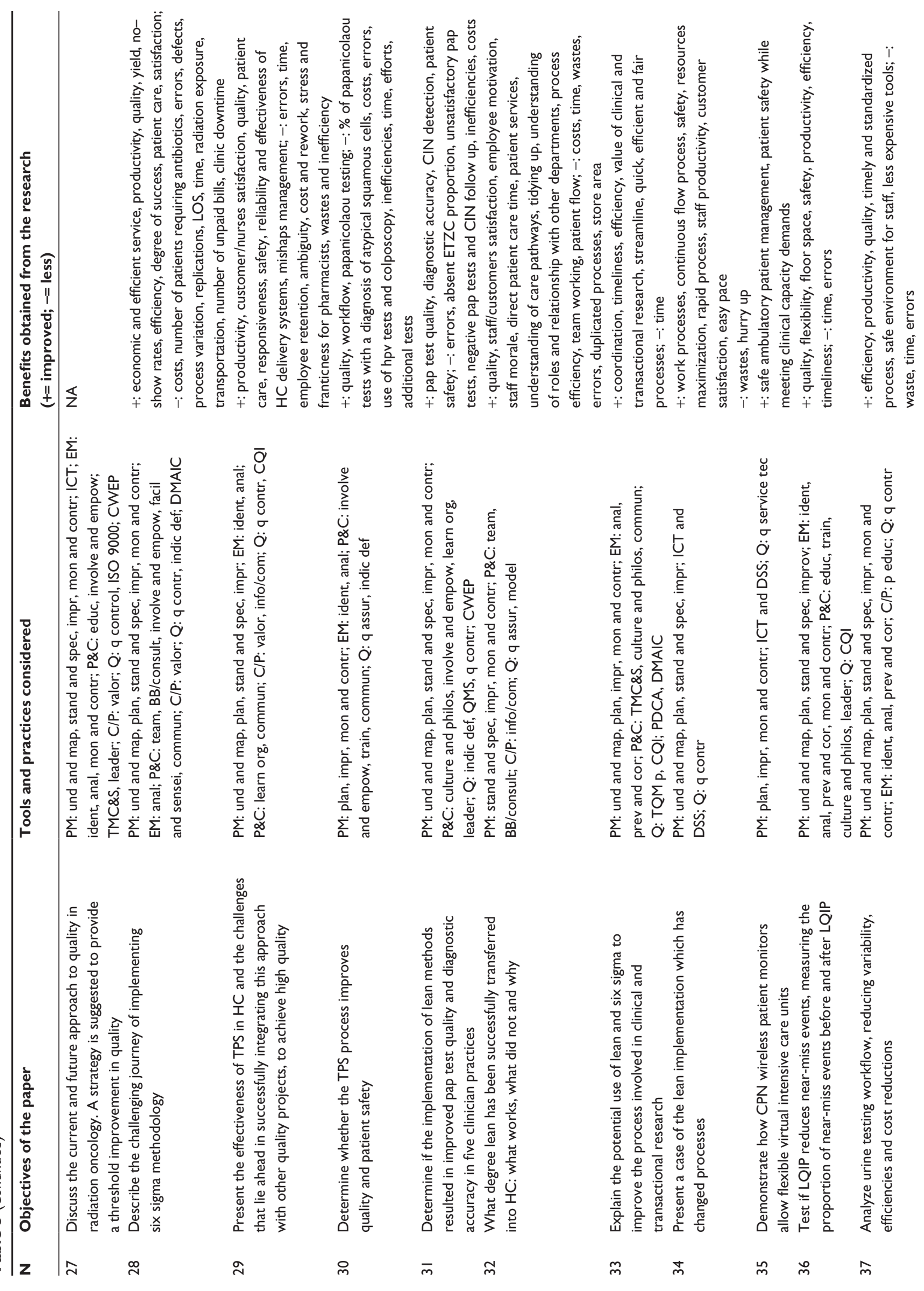



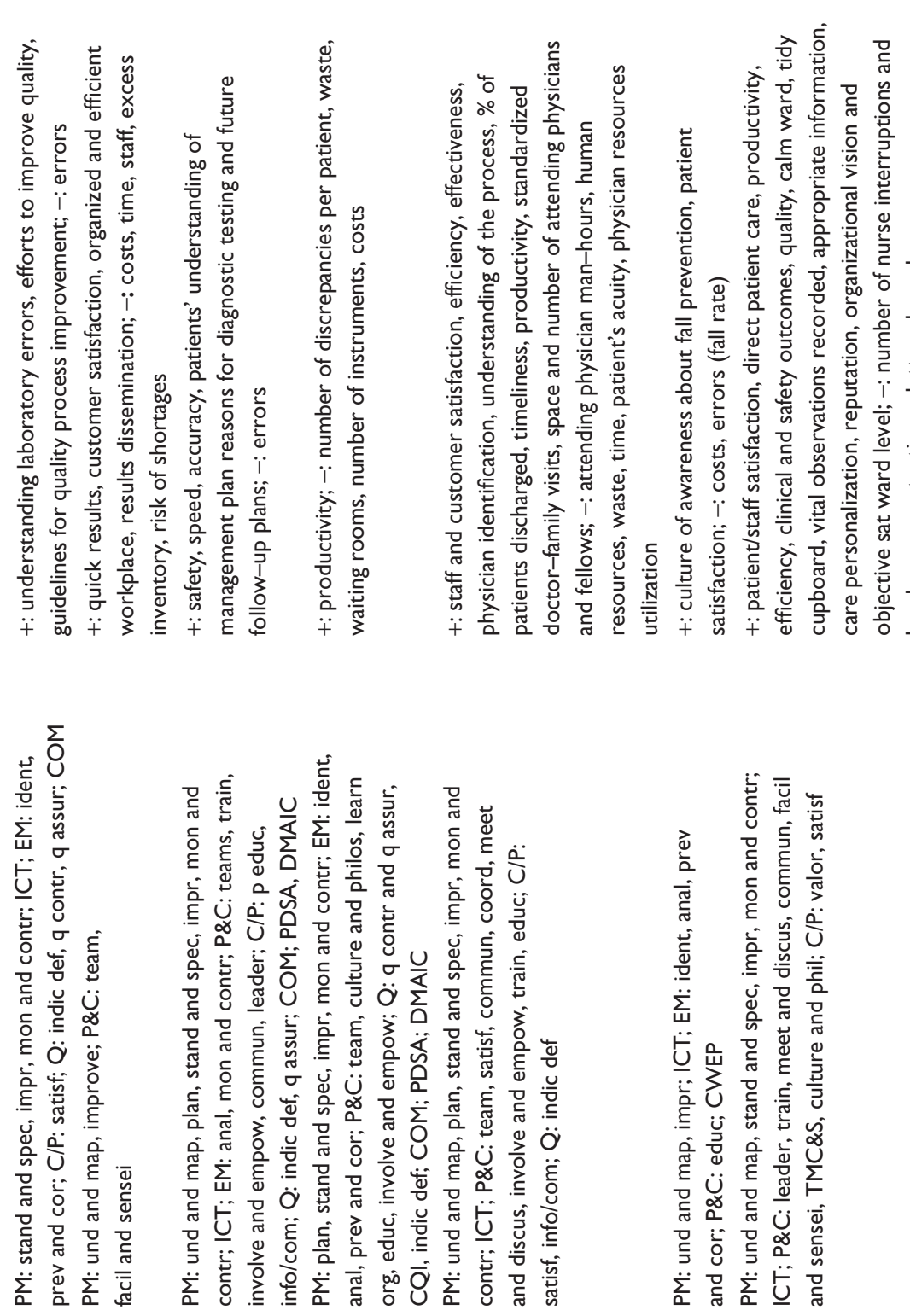

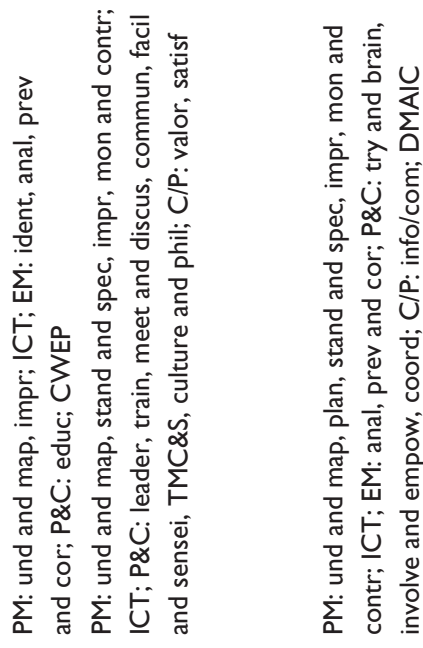
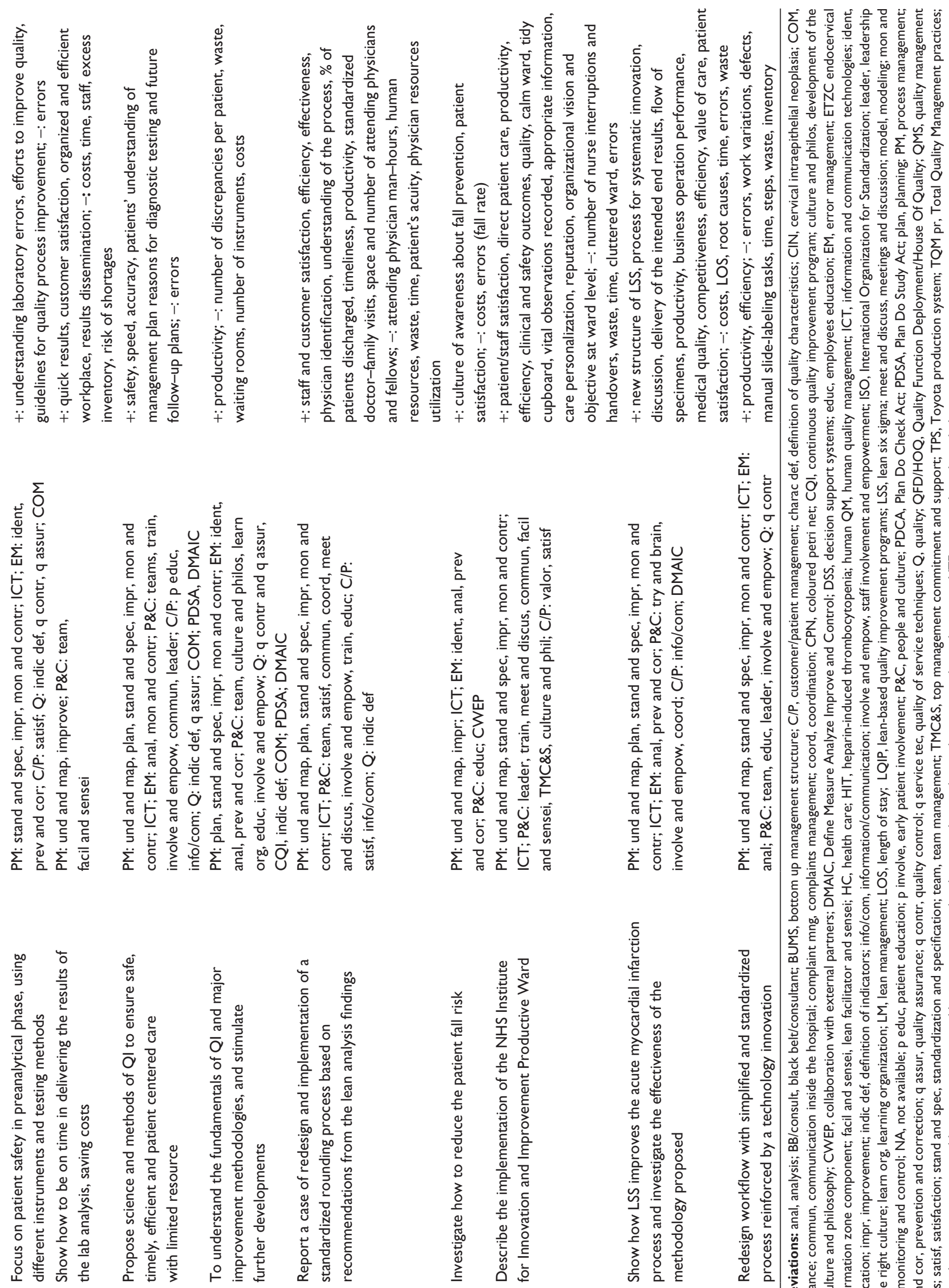

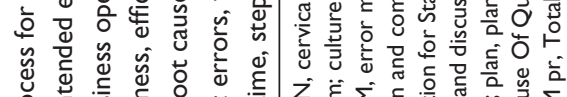

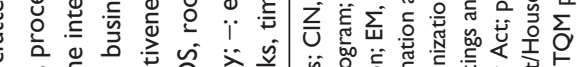

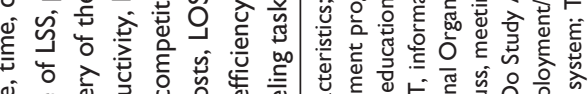

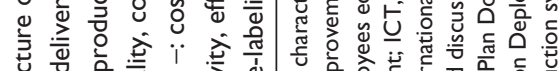

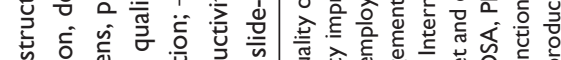

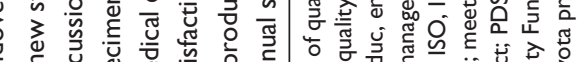

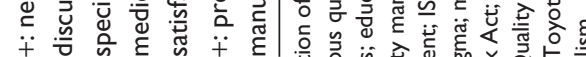

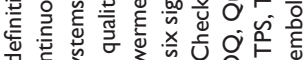

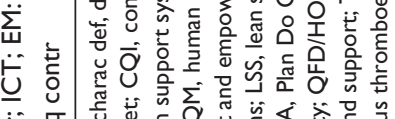

0
0
0

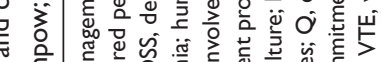

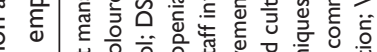

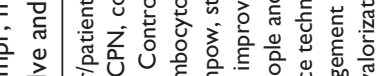

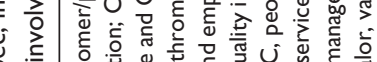

然

方蓄

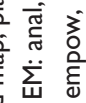

焉

芒害竞 
maximizing value for customer), customer-supplier connections and communication, complaints management, early patient involvement, and patient education.

Most of the analyzed papers aimed to describe the implementation of new managerial techniques and methodologies applied in health care, with the main purpose of achieving high quality and patient safety by improving workflows and efficiency and reducing errors. Table 3 shows the objectives, tools, and practices considered and the benefits of the research. It underscores that techniques relating to process management are always adopted, especially for process understanding and mapping (87\% of papers), and that different LM tools are used for process improvement. Within the area of people and culture, team building, employee education, and culture are also emphasized, while ICT is often adopted as a support instrument. The benefits obtained mostly relate to higher productivity and efficiency, a reduced amount of time spent in executing activities, reduced costs, improved accuracy, and fewer errors.

In Table 4, it can be observed that in all cases tools and practices of the process management type are used (100\% of papers). Also widely used are those of the people and culture category ( $89 \%$ ), followed by error management (72\%), quality (54\%), and ICT and DSS (48\%).

Moreover, it is interesting to observe that error management techniques are frequently used in hospitals as a whole, laboratory units, and emergency departments, while quality management tools and practices are mostly used in laboratory units and when the focus is the whole hospital. ICT and DSS are used in preference if the focus is the whole hospital. Finally, customer/patient management tools are much used practices when focusing on emergency departments.

\section{Discussion}

This review has highlighted critical factors in planning and implementing safe, lean projects, meaning process improvement projects, following an HLM approach and stressing safety performance, in addition to traditional cost and time benefits. These critical factors have been identified examining recurrent lessons learned from the reviewed literature. They are detailed in four categories as follows:

1. Culture, organization, and communication. Before starting a lean project, it is important to overcome resistance by developing an appropriate organizational climate and culture. Resistance can be surmounted by adopting models of behavior change. The hierarchical blame and shame culture should be replaced with one of safety and continuous improvement, and developing a learning organization. Staff have to be improved through education, training, motivation, involvement, empowerment, and valorization. An appropriate multidisciplinary team should be built and facilitators, champions, sponsors, and change agents should be identified.

Furthermore, changes should be implemented by employees identifying leaders and problem solvers inside the health care organization, with scholars, consultants, experts, and external stakeholders being involved as key collaborators. In addition, instead of focusing on shortterm results, a long-term perspective should be adopted, with the aim of developing a culture of quality and safety reporting and continual and structured problem-solving that avoids a quick-fix mentality. HLM can be applied at all levels, but benefits for the whole organization will be achieved when it is applied at a strategic level. The HLM approach should be aligned with the hospital's strategy

Table 4 Category of tools and practices adopted in literature per field of applications considered in literature

\begin{tabular}{|c|c|c|c|c|c|c|c|c|c|}
\hline \multirow{2}{*}{$\begin{array}{l}\text { Category of tools } \\
\text { and practices }\end{array}$} & \multicolumn{7}{|c|}{ Field of application } & \multirow{2}{*}{$\begin{array}{l}\text { Total frequency } \\
\text { of tools }\end{array}$} & \multirow{2}{*}{$\begin{array}{l}\% \text { on total } \\
\text { papers }\end{array}$} \\
\hline & LAB & Emergency & Radiology & Gynecology & HG & PC & Others* & & \\
\hline Process management & 14 (100\%) & $4(100 \%)$ & $3(100 \%)$ & $2(100 \%)$ & II (I00\%) & $3(100 \%)$ & $9(100 \%)$ & 46 & $100 \%$ \\
\hline People and culture & II (79\%) & $4(100 \%)$ & $3(100 \%)$ & $2(100 \%)$ & $10(9 \mid \%)$ & $3(100 \%)$ & $8(89 \%)$ & 41 & $89 \%$ \\
\hline Error management & 10 (7I\%) & $3(75 \%)$ & $3(100 \%)$ & I (50\%) & $9(82 \%)$ & $3(100 \%)$ & $4(44 \%)$ & 33 & $72 \%$ \\
\hline Quality management & 10 (7I\%) & I (25\%) & I (33\%) & $2(100 \%)$ & $7(64 \%)$ & $0(0 \%)$ & $4(44 \%)$ & 25 & $54 \%$ \\
\hline ICT and DSS & $4(29 \%)$ & $2(50 \%)$ & I (33\%) & $0(0 \%)$ & $8(73 \%)$ & I (33\%) & $6(67 \%)$ & 22 & $48 \%$ \\
\hline $\begin{array}{l}\text { Customer/patient } \\
\text { management }\end{array}$ & $5(36 \%)$ & $3(75 \%)$ & $3(100 \%)$ & $0(0 \%)$ & $2(18 \%)$ & I (33\%) & $4(44 \%)$ & 18 & $39 \%$ \\
\hline Compliance & $2(14 \%)$ & $0(0 \%)$ & I (33\%) & $0(0 \%)$ & $3(27 \%)$ & I (33\%) & I (I I\%) & 8 & $17 \%$ \\
\hline $\begin{array}{l}\text { Total number of } \\
\text { papers }\end{array}$ & 14 & 4 & 3 & 2 & II & 3 & 9 & 46 & \\
\hline $\begin{array}{l}\% \text { Papers per field } \\
\text { of application/total } \\
\text { papers }\end{array}$ & $30 \%$ & $9 \%$ & $6.5 \%$ & $4 \%$ & $24 \%$ & $6.5 \%$ & $20 \%$ & & \\
\hline
\end{tabular}

Note: *Aggregated because there was only one paper per field of application.

Abbreviations: DSS, data and systems management; ICT, information and communication technologies; LAB, laboratory; HG, Hospital in General; PC, process of care. 
and values. The ethics and culture of professionals should be consistent with those of the organization. To achieve successful outcomes, clear, consistent, direct, multidimensional, and frequent communication should take place among providers and between patients and providers, creating a climate of transparency and honesty. To obtain satisfactory results, the top management needs to provide commitment and support. The leadership of individuals appropriately trained and with the right culture is also paramount.

2. Process management (PM). With respect to PM, a systematic and proactive approach should be adopted, including the following phases: understanding (each step and task should be described with all competencies, standards of performance), managing, improving (usually changing the process design, standardizing, and specifying), and controlling to prevent system failures. It is also important to valorize the planning phase. Most problems are the result of system design issues. These can be solved through improved and simplified process redesign, with better connections and QMS, highlighting problems in real time and continually striving to understand their root causes, solving them immediately and adopting a system-wide approach. HLM can help enhance the ability to identify changes needed, especially with regard to policies and practices, in order to implement and sustain the desired quality improvements. Tools and practices connected with PM contribute to reducing errors and variations, in addition to improving the operational performance, effectiveness, and efficiency of clinical processes.

3. Error management (EM). The literature provides useful indications for EM. First, risks should be detected and then prevented by revising the risk-assessment process and developing a prevention strategy that should give priority to basic and cost-effective preventive care, instead of therapy care, following LSS and common sense. The tools need to focus mostly on the identification, prevention, and mitigation of errors. In particular, mechanisms of error detection are important because they increase awareness and process reliability. To better detect risks and errors, everyone should be involved (including families of patients) in safety and quality reporting, and a culture of proactive error reduction with double checks should be developed.

4. Patient/customer management. Focusing on adding and creating value for patients and listening to patients' voices are fundamental for overcoming resistance to changes. The implementation of HLM differs, depending on how the customer and customer value are defined. However, the most important point is that the customer-supplier connection should not be ambiguous and that the response to the customer has to be on-demand, defect-free, one-by-one, waste free, immediate, and safe.

Other guidelines that support these four categories deserve to be underscored:

- Quality management has to become integral, ${ }^{17}$ and HLM should be adopted to improve quality, rather than lower costs, following the patients' view of quality; $23,68,76$

- the adoption of ICT and DSS can support PM in all its phases; for example, in computerized physician ordering systems, barcoding, timeline monitoring systems, patient or specimen tracking, patient identification, and EMR databases. ${ }^{26,31,44,50,53,54,56-58,61,65,70,71,74,78}$ According to Sloane and Gehlot, ${ }^{71}$ ICT and some simulation tools should become a routine part of risk management. Moreover, robust data mining environments should be created and the use of ICT should be enlarged, as these could facilitate patient safety and error reduction and support the measurement of HLM effectiveness. ${ }^{21,26,50,65}$ However, investments in new technologies and automation should be considered only after process redesign. ${ }^{33,66,67}$

- Several authors have highlighted that positive results could be attributed to the Hawthorne effect. ${ }^{19,22,56,63,74}$ This is a temporary effect due to participation in the studies of particular contexts, as Wickström and Bendix $^{79}$ have discussed in depth. However, Raab et al ${ }^{67}$ have asserted that it is possible to achieve sustained improvements with HLM. To ensure sustainability and successful implementation of projects, the following key steps should be addressed: setting a focused aim, articulating time frames, identifying measurable goals, and following a properly planned iterative approach. ${ }^{26,73,59}$ Furthermore, new processes should be implemented in off-peak times, and interventions should be executed following a logical sequence. ${ }^{63}$ Periodically reviewing metrics leads to long-term sustainability. ${ }^{26}$ More research is needed using appropriate and consistent metrics to understand and measure the impact of HLM on quality, patient safety, and employee satisfaction and wellbeing. ${ }^{19,21,56,62,76}$

Figure 1 depicts the four main categories of guidelines with their associated references for critical factors and the supporting areas. 


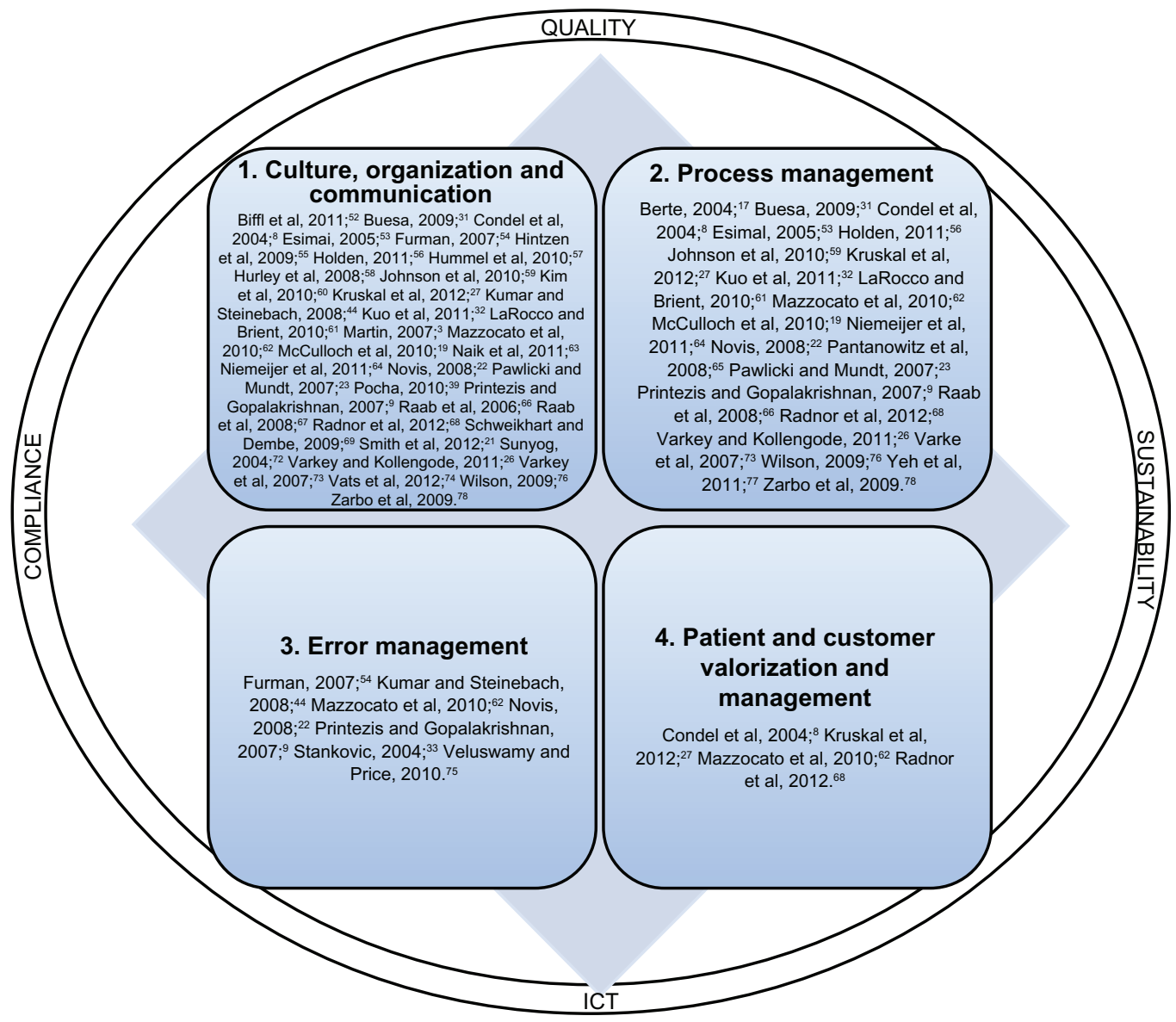

Figure I Guidelines for successful safety and lean project implementation.

Abbreviation: ICT, Information and communication technologies.

\section{Conclusion}

The purpose of this paper was to describe the techniques, tools, and practices adopted in health care to improve quality and patient safety and reduce costs and errors. The results of the literature review demonstrate that a variety of managerial tools are being implemented to achieve these aims. Traditional methodologies are accompanied by ongoing quality control and quality assurance, as well as proactive quality improvement and process improvement approaches, such as SS and LM. All these techniques should be implemented, together with others, such as TQM, and supported by ICT to reduce errors and ensure high quality and patient safety. ${ }^{20,30,65,73}$

In all the papers considered, tools and practices are being adopted for process management, especially for understanding and mapping processes. It is interesting to also underscore the widespread use of tools and practices of error management. According to some scholars, HLM implementation should be reported, and the results should be disseminated ${ }^{14,22,56}$ because positive and negative results and details of the implementation in various sectors can suggest and drive replications in other organizations..$^{56,62,72,74}$ In addition, factors that lead to positive changes or failures and contextual factors should be studied in depth. ${ }^{21,62}$ Some authors doubt whether HLM can be appreciated and replicated in other departments or organizations; an appropriate adaptation should be outlined. However, application of HLM stimulates discussion about how to solve system and process issues and improve quality and patient safety. ${ }^{22,60,68,74}$ Most of the analyzed papers have underscored the limits of HLM and barriers to its implementation, ${ }^{9,21,31,32,39,52,54,56,57,60,62,63,65,66,68,78}$ demonstrating that HLM cannot be successfully implemented without considering the proper critical factors and precautions highlighted in the previous section of this paper.

In conclusion, the guidelines that have emerged from this research concern (Figure 1): 1) culture, organization, and communication; 2) process management; 3 ) error management; and 4) customer/patient management and the issues that support it, such as ICT, quality, sustainability, and compliance. 
This literature review has analyzed the main research efforts that have considered aspects of both HLM and CRM, providing references to key published works worldwide. The results from these studies were employed to provide an overview of the managerial practices and tools used to overcome current managerial health care challenges and the critical factors that must be considered for successful implementation of safety and lean projects. Starting from the key concepts and indications highlighted in this paper (Table 3 and Figure 1), both future research (conducted by academics) and safety and lean projects in a health care context (conducted by managers) should be developed.

Although the current study provides an important contribution to the field, the available knowledge of its issues is insufficient at this early stage, and practical and academic studies are still limited. Despite the proposed guidelines should be further tested with empirical research, they suggest potential tools, practices, and critical factors to be considered to achieve successful implementation of lean and safety projects, as they emerged from literature analysis. Future research should further test, formalize, and develop knowledge and experience in the field to determine the potential synergy between HLM and CRM, developing in depth the reference scheme in Figure 1 and defining operative guidelines. In particular, the next steps suggested for future studies are to:

- map other experiences in the field in order to understand which tools, practices, and critical analyses are being considered, validating and integrating the guidelines proposed in this research;

- a larger database of previous experiences should permit analysis and verification in a quantitative way of the connections between objectives, tools, and results, also expanding the context of applications (other organizational units, care process, etc);

- develop indicators and measures that should be adopted to evaluate the costs and quality results obtained after the implementation of projects;

- investigate the possibility of creating a comprehensive synergic methodology that combine the benefits of HLM and CRM.

Future developments based on the indications and lessons developed from this literature review could provide solutions to help society obtain a higher level of health care in today's difficult economic and political climate of decreasing resources.

\section{Disclosure}

The authors report no conflicts of interest in this work.

\section{References}

1. Campbell SM, Roland MO, Buetow SA. Defining quality of care. Soc Sci Med. 2000;51(11):1611-1625.

2. Blumenthal D. Part 1: quality of care - what is it? N Engl J Med. 1996;335(12):891-894.

3. Martin W. Special report: quality of care survey. Quality models: selecting the best model to deliver results. Physician Exec. 2007;33(3): 24-31.

4. Laffel G, Blumenthal D. The case for using industrial quality management science in health care organizations. JAMA. 1989;262(20): 2869-2873.

5. Lohr KN, Donaldson MS, Harris-Wehling J. Medicare: a strategy for quality assurance, V: Quality of care in a changing health care environment. QRB Qual Rev Bull. 1992;18(4):120-126.

6. Agency for Healthcare Research and Quality. Testimony on Health Care Quality. Rockville; AHRQ Publications: 1997. Available from: http://archive.ahrq.gov/news/test1028.htm. Accessed May 10, 2013.

7. Spear S, Bowen HK. Decoding the DNA of the Toyota production system. Harv Bus Rev. 1999;77:96-108.

8. Condel JL, Sharbaugh DT, Raab SS. Error-free pathology: applying lean production methods to anatomic pathology. Clin Lab Med. 2004;24(4):865-899.

9. Printezis A, Gopalakrishnan M. Current pulse: can a production system reduce medical errors in health care? Qual Manag Health Care. 2007;16(3):226-238.

10. Agency for Healthcare Research and Quality. National Health Care Disparities Report. Rockville; AHRQ Publications: 2011. Available from: http://www.ahrq.gov/research/findings/nhqrdr/nhqr11/nhqr11. pdf. Accessed May 10, 2013.

11. Institute of Medicine. Crossing the Quality Chasm: A New Health System for the 21st Century. Washington; National Academy Press: 2001.

12. Lohr KN. Medicare: A Strategy for Quality Assurance. Volume I. Washington; National Academies Press: 1990.

13. Donabedian A. The quality of care. How can it be assessed? JAMA. 1999;260(12):1743-1748.

14. Herring L. Lean experience in primary care. Qual Prim Care. 2009;17(4):271-275.

15. National Priorities Partnership. National Priorities and Goals: Aligning our Efforts to Transform America's Healthcare. Washington: National Quality Forum; 2008.

16. Schwappach DL. Frequency of and predictors for patient-reported medical and medication errors in Switzerland. Swiss Med Wkly. 2011;141:w13262.

17. Berte LM. Patient safety: getting there from here-quality management is the best patient safety program. Clin Leadersh Manag Rev. 2004;18(6):311-315.

18. Vincent C. Risk, safety, and the dark side of quality. BMJ. 1997;314(7097):1775-1776.

19. McCulloch P, Kreckler S, New S, Sheena Y, Handa A, Catchpole K. Effect of a "Lean" intervention to improve safety processes and outcomes on a surgical emergency unit. BMJ. 2010;341:c5469.

20. Stankovic AK. The laboratory is a key partner in assuring patient safety. Clin Lab Med. 2004;24(4):1023-1035.

21. Smith ML, Wilkerson T, Grzybicki DM, Raab SS. The effect of a lean quality improvement implementation program on surgical pathology specimen accessioning and gross preparation error frequency. Am $J$ Clin Pathol. 2012;138(3):367-373.

22. Novis DA. Reducing errors in the clinical laboratory: a lean production system approach. Lab Med. 2008;39(9):521-529.

23. Pawlicki T, Mundt AJ. Quality in radiation oncology. Med Phys. 2007;34(5):1529-1540.

24. Verbano C, Turra F. A human factors and reliability approach to clinical risk management: evidence from Italian cases. Safety Sci. 2010;48(5):625-639.

25. Verbano C, Venturini K. Development paths of risk management: approaches, methods and fields of application. Journal of Risk Research. 2011;14(5):519-550. 
26. Varkey P, Kollengode A. A framework for healthcare quality improvement in India: the time is here and now! J Postgrad Med. 2011;57(3):237-241.

27. Kruskal JB, Reedy A, Pascal L, Rosen MP, Boiselle PM. Quality initiatives: lean approach to improving performance and efficiency in a radiology department. Radiographics. 2012;32(2):573-587.

28. Womack JP, Jones DT. Lean Thinking: Banish Waste and Create Wealth in your Corporation. New York; Free Press: 2003.

29. Liker, JK. The Toyota Way. New York; McGraw-Hill: 2004.

30. Das B. Validation protocol: first step of a lean-total quality management principle in a new laboratory set-up in a tertiary care hospital in India. Indian J Clin Biochem. 2011;26(3):235-243.

31. Buesa RJ. Adapting lean to histology laboratories. Ann Diagn Pathol. 2009;13(5):322-333.

32. Kuo AM, Borycki E, Kushniruk A, Lee TS. A healthcare Lean Six Sigma System for postanesthesia care unit workflow improvement. Qual Manag Health Care. 2011;20(1):4-14.

33. Stankovic AK, DiLauri E. Quality improvements in the preanalytical phase: focus on urine specimen workflow. Clin Lab Med. 2008;28(2): 339-350, viii.

34. Dahlgaard JJ, Pettersen J, Dahlgaard-Park SM. Quality and lean health care: A system for assessing and improving the health of healthcare organisations. Total Quality Management and Business Excellence. 2011;22(6):673-689.

35. Ohno T. Toyota Production System: Beyond Large-Scale Production. Portland; Productivity Press: 1988.

36. Institute for Healthcare Improvement. Going Lean in Health Care. IHI Innovation Series White Paper. Cambridge: Institute for Healthcare Improvement; 2005. Available from: http://www.entnet.org/Practice/ qualityimprovement/upload/GoingLeaninHealthCareWhitePaper-3.pdf. Accessed August 7, 2013.

37. Bush RW. Reducing waste in US health care systems. JAMA. 2007;297(8):871-874

38. Jimmerson C, Weber D, Sobek DK. Reducing waste and errors: piloting lean principles at Intermountain Healthcare. Jt Comm J Qual Patient Saf. 2005;31(5):249-257.

39. Pocha C. Lean Six Sigma in health care and the challenge of implementation of Six Sigma methodologies at a Veterans Affairs Medical Center. Qual Manag Health Care. 2010;19(4):312-318.

40. Bodenheimer T. High and rising health care costs. Part 1: seeking an explanation. Ann Intern Med. 2005;142(10):847-854.

41. Barclays. UK healthcare. Sector outlook. Third quarter 2012. London: Barclays Bank PLC; 2012. Available from: http://www. barclayscorporate.com/content/dam/corppublic/corporate/Documents/ sector_expertise/healthcare_outlook.pdf. Accessed June 11, 2013.

42. OECD. Health at a Glance Europe 2012. OECD Publishing; 2012. Available from: http://ec.europa.eu/health/reports/docs/health_ glance_2012_en.pdf. Accessed May 9, 2013.

43. Marshall M, Øvretveit J. Can we save money by improving quality? BMJ Qual Saf. 2011;20(4):293-296.

44. Kumar S, Steinebach M. Eliminating US hospital medical errors. Int J Health Care Qual Assur. 2008;21(5):444-471.

45. Øvretveit J. Does Improving Quality Save Money? A Review of Evidence of which Improvements to Quality Reduce Costs to Health Service Providers. London: The Health Foundation; 2009.

46. Denyer D, Tranfield D. Producing a Systematic Review. In: The SAGE handbook of organizational research methods. Buchanan DA, Bryman A, editors. London: SAGE Publications Ltd; 2009:670-689.

47. Pawson R. Evidence-Based Policy: A Realist Perspective. London: SAGE Publications Ltd; 2006.

48. Denyer D, Tranfield D, Van Aken JE. Developing design propositions through research synthesis. Organ Stud. 2008;29(3):393-413.

49. Brereton P, Kitchenham BA, Budgen D, Turner M, Khalil M. Lessons from applying the systematic literature review process within the software engineering domain. $J$ Syst Software. 2007;80(4); $571-583$.
50. Becich MJ, Gilbertson JR, Gupta D, Patel A, Grzybicki DM, Raab SS. Pathology and patient safety: the critical role of pathology informatics in error reduction and quality initiatives. Clin Lab Med. 2004;24(4): 913-943, vi.

51. Benitez Y, Forrester L, Hurst C, Turpin D. Hospital reduces medication errors using DMAIC and QFD. Qual Prog. 2007;40(1):38-45.

52. Biffl WL, Beno M, Goodman P, et al. "Leaning" the process of venous thromboembolism prophylaxis. Jt Comm J Qual Patient Saf. 2011;37(3):99-109.

53. Esimai, G. Lean six sigma reduces medication errors. Qual Prog. 2005;38(4):51-57.

54. Furman C, Caplan R. Applying the Toyota Production System: using a patient safety alert system to reduce error. Jt Comm J Qual Patient Saf. 2007;33(7):376-386.

55. Hintzen BL, Knoer SJ, Van Dyke CJ, Milavitz BS. Effect of lean process improvement techniques on a university hospital inpatient pharmacy. Am J Health Syst Pharm. 2009;66(22):2042-2047.

56. Holden RJ. Lean Thinking in emergency departments: a critical review. Ann Emerg Med. 2011;57(3):265-278.

57. Hummel J, Evans PC, Lee H. Medication reconciliation in the emergency department: opportunities for workflow redesign. Qual Saf Health Care. 2010;19(6):531-535.

58. Hurley B, Levett JM, Huber C, Taylor TL. Using lean six sigma ${ }^{\circledR}$ tools to compare INR measurements from different laboratories within a community. Quality management in health care. 2008;20(1):4-15.

59. Johnson CD, Miranda R, Aakre KT, Roberts CC, Patel MD, Krecke KN. Process improvement: what is it, why is it important, and how is it done? AJR Am J Roentgenol. 2010;194(2):461-468.

60. Kim CS, Lukela MP, Parekh VI, et al. Teaching internal medicine residents quality improvement and patient safety: a lean thinking approach. Am J Med Qual. 2010;25(3):211-217.

61. LaRocco M, Brient K. Interdisciplinary process improvement for enhancing blood transfusion safety. J Healthc Qual. 2010;32(2):29-34.

62. Mazzocato P, Savage C, Brommels M, Aronsson H, Thor J. Lean thinking in healthcare: a realist review of the literature. Qual Saf Health Care. 2010;19(5):376-382.

63. Naik T, Duroseau Y, Zehtabchi S, et al. A structured approach to transforming a large public hospital emergency department via lean methodologies. J Healthc Qual. 2011;34(2):86-97.

64. Niemeijer GC, Does RJ, de Mast J, Trip A, van den Heuvel J. Generic project definitions for improvement of health care delivery: a case-based approach. Qual Manag Health Care. 2011;20(2):152-164.

65. Pantanowitz L, Hornish M, Goulart RA. Informatics applied to cytology. Cytojournal. 2008;5(1):16-27.

66. Raab SS, Andrew-Jaja C, Condel JL, Dabbs DJ. Improving Papanicolaou test quality and reducing medical errors by using Toyota production system methods. Am J Obstet Gynecol. 2006;194(1):57-64.

67. Raab SS, Andrew-Jaja C, Grzybicki DM, et al. Dissemination of Lean methods to improve Pap testing quality and patient safety. J Low Genit Tract Dis. 2008;12(2):103-110.

68. Radnor ZJ, Holweg M, Waring J. Lean in healthcare: the unfilled promise? Soc Sci Med. 2012;74(3):364-371.

69. Schweikhart SA, Dembe AE. The applicability of Lean and Six Sigma techniques to clinical and translational research. $J$ Investig Med. 2009;57(7):748-755.

70. Serrano L, Hegge P, Sato B, Richmond B, Stahnke L. Using LEAN principles to improve quality, patient safety, and workflow in histology and anatomic pathology. Adv Anat Pathol. 2010;17(3):215-221.

71. Sloane EB, Gehlot V. Use of coloured petri net models in planning, design, and simulation of intelligent wireless medical device networks for safe and flexible hospital capacity management. IJNVO. 2007;4(2): 118-129.

72. Sunyog M. Lean Management and Six-Sigma yield big gains in hospital's immediate response laboratory. Quality improvement techniques save more than $\$ 400,000$. Clin Leadersh Manag Rev. 2004;18(5): $255-258$. 
73. Varkey P, Reller MK, Resar RK. Basics of quality improvement in health care. Mayo Clin Proc. 2007;82(6):735-739.

74. Vats A, Goin KH, Villarreal MC, Yilmaz T, Fortenberry JD, Keskinocak P. The impact of a lean rounding process in a pediatric intensive care unit. Crit Care Med. 2012;40(2):608-617.

75. Veluswamy R, Price R. I've fallen and I can't get up: reducing the risk of patient falls. Physician Exec. 2010;36(3):50-53.

76. Wilson G. Implementation of Releasing Time to Care - the productive ward. J Nurs Manag. 2009;17(5):647-654.
77. Yeh HL, Lin CS, Su CT, Wang PC. Applying lean six sigma to improve healthcare: An empirical study. AJBM. 2011;5(31):12356-12370.

78. Zarbo RJ, Tuthill JM, D'Angelo R, et al. The Henry Ford Production System: reduction of surgical pathology in-process misidentification defects by bar code-specified work process standardization. Am J Clin Pathol. 2009;131(4):468-477.

79. Wickström G, Bendix T. The "Hawthorne effect" - what did the original Hawthorne studies actually show? Scand J Work Environ Health. 2000;26(4):363-367.

\section{Publish your work in this journal}

Therapeutics and Clinical Risk Management is an international, peerreviewed journal of clinical therapeutics and risk management, focusing on concise rapid reporting of clinical studies in all therapeutic areas, outcomes, safety, and programs for the effective, safe, and sustained use of medicines. This journal is indexed on PubMed Central, CAS
EMBase, Scopus and the Elsevier Bibliographic databases. The manuscript management system is completely online and includes a very quick and fair peer-review system, which is all easy to use. Visit http://www.dovepress.com/testimonials.php to read real quotes from published authors.

Submit your manuscript here: http://www.dovepress.com/therapeutics-and-clinical-risk-management-journal 